\title{
Molecular Characterization of a Novel Putative Partitivirus Infecting Cytospora sacchari, a Plant Pathogenic Fungus
}

\author{
Mahtab Peyambari ${ }^{1}$, Mina Koohi Habibi ${ }^{1}$, Khalil-Berdi Fotouhifar ${ }^{1}$, Akbar Dizadji ${ }^{1}$ and Marilyn J. Roossinck ${ }^{2 *}$ \\ ${ }^{1}$ Department of Plant Protection, Faculty of Agricultural Science and Engineering, College of Agriculture and Natural \\ Resources, University of Tehran, Karaj, Iran \\ ${ }^{2}$ The Huck Institutes of the Life Sciences, Center for Infectious Disease Dynamics, Millennium Science Complex, The \\ Pennsylvania State University, University Park, PA 16802, USA
}

(Received on January 20, 2014; Revised on March 3, 2014; Accepted on March 11, 2014)

Three double-stranded RNAs (dsRNAs), approximately $1.85,1.65$ and $1.27 \mathrm{~kb}$ in size, were detected in an isolate of Cytospora sacchari from Iran. Partial nucleotide sequence revealed a 1,284 bp segment containing one ORF that potentially encodes a 405 aa protein. This protein contains conserved motifs related to RNA dependent RNA polymerases (RdRp) that showed similarity to RdRps of partitiviruses. The results indicate that these dsRNAs represent a novel Partitivirus that we tentatively designate Cytospora sacchari partitivirus (CsPV). Treatment of the fungal strain by cyclohexamide and also hyphal tip culture had no effect on removing the putative virus. Phylogenetic analysis of putative RdRp of CsPV and other partitiviruses places CsPV as a member of the genus Partitivirus in the family Partitiviridae, and clustering with Aspergillus ochraceous virus 1.

Keywords : Cytospora, mycovirus, partitivirus, virus evolution

Fungal viruses or mycoviruses are widespread among all major taxa of fungi (Ghabrial and Suzuki, 2009). Although many Mycoviruses are apparently symptomless in their hosts, some affect mycelial growth, sporulation, pigmentation and, for pathogenic fungi, virulence of the fungal hosts (Pearson et al., 2009). Virus effects on fungal virulence can be up-regulating or down-regulating (called hypervirulence and hypovirulence, respectively). Attenuation of virulence by mycoviruses has led to their use as biological control for phytopathogenic fungi (Nuss, 1992). The fungus-mycovirus system Cryphonecteria parasitica, the casual agent of chestnut blight disease, and Cryphonecteria hypovirus 1

*Corresponding author.

Phone) +1-814-865-2292, FAX) +1-814-863-7217

E-mail)mjr25@psu.edu
(CHV1) is a well-characterized example of hypovirulence (Milgroom and Cortesi 2004; Nuss, 2005). Rosellinia necatrix megabirnavirus 1 is also a potential viral agent for biological control of the white root rot disease caused by Rosellinia necatrix (Chiba et al., 2009). An example of hypervirulence is the double-stranded RNA (dsRNA) element of Nectria radicicola that is associated with enhanced virulence of the host fungus (Ahn and Lee, 2001).

Mycoviruses appear to lack any extracellular phase in their life cycle so their transmission is thought to be intracellular, horizontally by hyphal anastomosis, and vertically by spores (Cortesi et al., 2001; Ghabrial and Suzuki, 2009). As with all viruses, they are dependent on their host for their replication (Park et al., 2006). Most mycoviruses have either single-stranded RNA (ssRNA) or dsRNA genomes (Ghabrial, 1998), although recently, a novel ssDNA mycovirus was discovered in Sclerotinia sclerotiorum (Yu et al., 2010). The ssRNA mycoviruses are classified into the families Hypoviridae, Narnaviridae, Endornaviridae, Alphaflexiviridae and Gammaflexiviridae (Ghabrial and Suzuki, 2009; King et al., 2012). Some ssRNA mycoviruses have not yet been classified into families. The dsRNA mycoviruses are classified into four families: Partitiviridae, Totiviridae, Reoviridae and Chrysoviridae, based on the number of genome segments, capsid structure and nucleotide sequences (King et al., 2012). Partitiviridae and Totiviridae members have a wide range of fungal host species, compared with the members of Reoviridae and Chrysoviridae families. Recently some novel dsRNA mycoviruses were reported that do not classify in any of these families, e.g., Rosellinia necatrix megabirnavirus 1 (Chiba et al., 2009) and Fusarium graminearum virus 3 (Yu et al., 2009). Increasing numbers of reported novel mycoviruses reflects the high diversity of mycoviruses and might help to increase our knowledge about the origin, ecology and evolutionary pathways of mycoviruses. 
The family Partitiviridae consists of four genera that have bipartite genomes (Ghabrial et al., 2008; Nibert et al., 2009); the members of the genus Partitvirus are reported to specifically infect fungi (King et al., 2012). Partitiviruses have isometric virions consisting of two unrelated, linear dsRNA segments, in the size range of 1.4-2.3 kbp. Each genome segment is packaged inside a separate viral capsid (Nibert et al., 2013). RNA1 codes for the RNAdependent RNA polymerase (RdRp) and RNA2 codes for the capsid protein (CP) (Ghabrial et al., 2008; King et al., 2012). However, an additional segment has been identified in some members of this family, which is presumed to be a satellite RNA (Chiba et al., 2013; Ghabrial et al., 2008).

Species of the fungus Cytospora Ehrenb. cause canker and dieback diseases in trees, shrubs and, rarely, herbaceous plants. The diseases affect cultivation, productivity and longevity of fruit trees, and ornamental and forest shrubs and trees (Adams et al., 2006; Fotouhifar et al., 2010). Cytospora species are classified into Valsaceae, Diaporthales, Ascomycota (Adams et al., 2005). Two species, C. tritici and C. sacchari, were reported from the monocotyledonous plants sugarcane (Saccharum officinarum L.) and wheat (Triticum aestivum L.), respectively (Adams et al., 2005). In Iran C. sacchari was reported as the causal agent of sheath rot disease of sugarcane from Khuzestan province (Taher-Khani et al., 2004). This species can also infect $S$. spontaneum and Holcus sorghum (Sorghum vulgare) (Sivanesan, 1983). A sexual form has not been reported for $C$. sacchari. Infected plants have leaves that become dry from the tips downwards and their sheaths are brown to black (Sivanesan, 1983). In severe infection, the whole sheath turns reddish-brown and eventually becomes necrotic (Taher-Khani et al., 2004). This infection can result in significant yield losses. The attempts to control Cytospora cankers with fungicides or resistant cultivars have had limited success (Snyder et al., 1989). Attenuated virulence in some plant pathogenic fungi is associated with the presence of dsRNA that leads to biological control of diseases. Hammar et al. (1989) reported that a hypovirulent isolate of Leucostoma persoonii, casual agent of peach canker, contained dsRNAs and exhibited abnormal culture morphology and reduced virulence. Recently a new Hypovirus, Valsa ceratosperma hypovirus 1 (VcHV1), has been identified in an isolate of Valsa ceratosperma (Yaegashi et al., 2012). However, VcHV1 did not affect colony morphology or fungal virulence in $V$. ceratosperma. To our knowledge, no dsRNA has yet been reported for $C$. sacchari.

In the present study, we identify and partially characterize a dsRNA mycovirus, tentatively named Cytospora sac- chari partitivirus (CsPV), isolated from C. sacchari isolate 125 , which was originally obtained from sugarcane in Khuzestan, Iran. Partial nucleotide sequence of this virus, sequence comparisons and phylogenetic analysis of putative $\mathrm{RdRp}$ indicate that CsPV is closely related to members of the genus Partitivirus, e.g., Penicillium stoloniferom virus $S$ (PsVS), Aspergillus ochraceous virus 1 (AoV1) and Ophiostoma Partitivirus 1 (OPV1) that belong to the family Partitiviridae. Attempts to remove the virus by treatment of the fungus with cyclohexamide and hyphal tip culture were unsuccessful.

\section{Materials and Methods}

Fungal isolate and growth conditions. C. sacchari 125 was originally isolated from diseased sugarcane that was collected from Khuzestan province, Iran (Fotouhifar, 2007). Isolate 125 was identified as a strain of $C$. sacchari by amplifying and sequencing of the internal transcribed spacer (ITS) region, ITS1-5.8S-ITS2, and comparing the sequence (GenBank accession no. EF447388) with those of other strains in Genbank (Fotouhifar et al., 2010). C. sacchari 125 was cultured on potato dextrose agar (PDA) at $25-27^{\circ} \mathrm{C}$ for $4-5$ days. Then five mycelial agar discs from the PDA plate were inoculated to $150 \mathrm{ml}$ potato dextrose broth (PDB) and cultured for $3-4$ days at $25-27^{\circ} \mathrm{C}$ with shaking. The biomass was extracted with Buchner funnel, lyophilized and then kept in $-20^{\circ} \mathrm{C}$ for extracting dsRNA.

dsRNA extraction. Viral dsRNA was extracted from isolate 125 by CF11 (Whatman, UK) cellulose chromatography as described by Dodds et al. (1984). In brief, mycelial tissue was ground by mortar and pestle in liquid nitrogen to a fine powder. Total nucleic acids were extracted from $40 \mathrm{mg}$ of mycelial powder using $800 \mu \mathrm{l} 2 \times \mathrm{STE}$ buffer $(20$ $\mathrm{ml}$ of $1 \mathrm{M}$ Tris (pH 8.0), $40 \mathrm{ml}$ of $5 \mathrm{M} \mathrm{NaCl}, 4 \mathrm{ml}$ of $0.5 \mathrm{M}$ EDTA (pH 8.0) and $936 \mathrm{ml}$ of sterile distilled water) and proteins were precipitated with $80 \mu 110 \%$ sodium dodecyl sulfate (SDS) and $800 \mu$ phenol-chloroform-isoamylalcohol (12:12:1). The resulting mixture was centrifuged at $5,000 \times \mathrm{g}$ for $10 \mathrm{~min}$, and exactly $700 \mu \mathrm{l}$ of the aqueous phase was mixed with $700 \mu \mathrm{l}$ chloroform-isoamylalcohol (24:1), followed by centrifugation to separate phases for 5 $\min , 13,000 \times \mathrm{g}$. Exactly $600 \mu \mathrm{l}$ of the aqueous phase was transferred to a $1.5 \mathrm{ml}$ microfuge tube, and the extracted nucleic acids adjusted with absolute ethanol to a final concentration of $15 \%$. The dsRNA was purified by chromatography on CF11 cellulose; the cellulose CF-11 was washed with $1 \times \mathrm{STE} / 15 \%$ ethanol and the dsRNA was eluted with $1 \times \mathrm{STE}$. The dsRNA was precipitated in $0.3 \mathrm{M}$ sodium ac- 
etate $(\mathrm{pH} 4)$ and $70 \%$ ethanol and was collected by centrifugation. The pellet was rinsed with $70 \%$ ethanol. The final dsRNA pellet was dissolved in $20 \mu \mathrm{l}$ Rase-free water and digested with DNase I and RNase A at high and low salt concentrations as described by Howitt et al. (1995). The final dsRNA was electrophoresed on a $0.8 \%$ agarose gel in TBE buffer stained with ethidium bromide, and observed under UV illumination. The dsRNA sample was stored at $-20^{\circ} \mathrm{C}$ for further steps.

Curing experiments. Cycloheximide treatments were used to eliminate dsRNA in isolate 125 . These treatments were carried out on PDA plates containing 25 and $50 \mu \mathrm{g}$ cycloheximide (Sigma, USA) per milliliter (Hammar et al., 1989). Mycelial plugs of isolate 125 were transferred onto treated PDA plates. Two replicates of each concentration were incubated at $25-27^{\circ} \mathrm{C}$. After 3 days, hyphal tips from the margins of the colonies were transferred to fresh PDA. This was repeated two times. Then mycelial plugs were cultured in PDB for 3-4 days. The dsRNA was extracted to investigate the effect of cycloheximide and hyphal tip culture on mycelial infection as described above.

RT-PCR, cloning and sequencing. DsRNA from isolate 125 was used for cDNA synthesis with tagged random hexamer primers using a protocol based on that of Roossinck et al. (2010). A $9 \mu \mathrm{l}$ aliquot of dsRNA was mixed with 1 $\mu 110 \mathrm{mM}$ TE buffer (10 mM Tris, $10 \mathrm{mM}$ EDTA, pH 7.5) and $2 \mu \mathrm{l}(20 \mu \mathrm{M})$ random primer 5'-CCT GAA TTC GGA TCC TCC N6-3'. The dsRNA was placed $2 \mathrm{~min}$ in boiling water for denaturing, and then chilled on ice. Eight $\mu$ of reverse transcription mixture containing $4 \mu \mathrm{l} 5 \times$ superscript buffer, $1 \mu \mathrm{dNTPs}$ (10 mM each), $2 \mu 1$ dithiothreitol (supplied by manufacturer) and $1 \mu \mathrm{l}$ Superscript III (Invitrogen, USA) was added to the sample, and the mixture was incubated on ice for $15 \mathrm{~min}$, and then placed at $50^{\circ} \mathrm{C}$ for $2 \mathrm{~h}$. The samples were removed from $50^{\circ} \mathrm{C}$ and treated with 1 $\mu \mathrm{l}(10 \mathrm{mg} / \mathrm{ml})$ of boiled ribonuclease A (Sigma, USA), and incubated at room temperature for $15 \mathrm{~min}$. The sample then was heated to $85^{\circ} \mathrm{C}$ for $2 \mathrm{~min}$, and the primers removed using a cycle pure kit (Omega, Bio-Tek, USA) according to the manufacturer's instructions. The sample was eluted in $30 \mu \mathrm{l}$ water. A $1.5 \mu \mathrm{l}$ aliquot of the cDNA was amplified in a total volume of $50 \mu \mathrm{l}$ containing a final concentration of 10× PCR buffer ( $30 \mathrm{mM} \mathrm{MgCl}_{2}$, Idaho Technologies), $0.2 \mathrm{mM}$ dNTPs, $2 \mu \mathrm{M}$ Tag primer 5'-CCT GAA TTC GGA TCC TCC-3', and 1 unit of Taq DNA polymerase (Promega, USA). The amplification was done in an Idaho Technologies Rapid Cycler II, using capillary tubes and the following program: $94^{\circ} \mathrm{C}$ for $1 \mathrm{~min} ; 65^{\circ} \mathrm{C} 0 \mathrm{~s} ; 72^{\circ} \mathrm{C} 5 \mathrm{~s}$, with a slope of 9 , followed by 40 cycles of $94^{\circ} \mathrm{C} 0 \mathrm{~s} ; 45^{\circ} \mathrm{C}$ $0 \mathrm{~s} ; 72^{\circ} \mathrm{C} 30 \mathrm{~s}$, with a slope of 5 , and a final $5 \mathrm{~min}$ at $72^{\circ} \mathrm{C}$ and $5 \mathrm{~min}$ at $37^{\circ} \mathrm{C}$. The amplified cDNAs were removed from capillary tubes, and were viewed after separation on $1.2 \%$ agarose gel and staining with ethidium bromide.

For cloning, the double stranded cDNAs were purified using a cycle pure kit (Omega, Bio-tek), and were ligated with pGEM-T vector using T4 DNA ligase according to manufacturer's instructions (Promega, USA). The recombinant vectors were transformed into competent cells of Escherichia coli strain JM101. The inserted clones were screened and amplified with M13 forward and reverse universal primers, using the program: $94^{\circ} \mathrm{C}$ for $15 \mathrm{~s}$, followed by 30 cycles of $94^{\circ} \mathrm{C} 15 \mathrm{~s} ; 54^{\circ} \mathrm{C} 6 \mathrm{~s} ; 72^{\circ} \mathrm{C} 3 \mathrm{~min}$ and a final $5 \mathrm{~min}$ at $72^{\circ} \mathrm{C}$ and $5 \mathrm{~min}$ at $37^{\circ} \mathrm{C}$. The amplified clones were sequenced using Applied Biosystems 3730XL. All clones were sequenced in both directions.

PCR was conducted to determine missing sequence gaps using specific primers, designed to amplifying a $300 \mathrm{bp}$ fragment (Table 1), and Taq DNA polymerase. The PCR conditions included an initial denaturation step of $15 \mathrm{~s}$ at $94^{\circ} \mathrm{C}$, followed by 35 cycles of $15 \mathrm{~s}$ at $94^{\circ} \mathrm{C}, 6 \mathrm{~s}$ at $53^{\circ} \mathrm{C}$ and $45 \mathrm{~s}$ at $72^{\circ} \mathrm{C}$, with a final of $5 \mathrm{~min}$ at $72^{\circ} \mathrm{C}$ and $5 \mathrm{~min}$ at $37^{\circ} \mathrm{C}$. PCR products, with a predicted size of $300 \mathrm{bp}$, were fractionated by gel electrophoresis on $1.2 \%$ agarose gels and stained with ethidium bromide. PCR products were cloned and sequenced as described above.

Sequence analysis. Sequence data were assembled using Geneious software version 6.1.2 (Drummond et al., 2011). The results were compared to databases with the both BlastN and BlastX against the GenBank nucleotide (nt) and non-redundant protein (nr) databases, respectively. The BLAST program is available in The National Center for Biotechnology Information (NCBI). The putative amino acid sequence of the isolate $125 \mathrm{RdRp}$ gene was compared to databases with BlastP. This putative RdRp and those of closely related viruses were obtained from the NCBI database, and aligned using the ClustalW program. After hand editing of the alignments these were used for phylogenetic analyses and tree construction using MrBayes (Huelsenbeck

Table 1. Specific primers used in this study

\begin{tabular}{cc}
\hline Primer name & Sequence $\left(5^{\prime}-3^{\prime}\right)$ \\
\hline $125(1)-\mathrm{F}$ & GAACCACGCTCAAGC \\
$125(1)-\mathrm{R}$ & GCATCTGACATACCTCCTC \\
$125(2)-\mathrm{F}$ & CAATTTGATCGTGATGTG \\
$125(2)-\mathrm{R}$ & CTTGTCTTCGGATCAGAG \\
\hline
\end{tabular}


and Ronquist, 2001) via the Geneious plugin. The rate matrix was set to a Poisson distribution with a gamma rate variation. The total chain length was 10,000 and branch lengths were unconstrained.

\section{Results and Discussion}

Identification of dsRNAs in $C$. sacchari 125 . Viruses of the family Partitiviridae have bi-segmented genomes containing two linear dsRNA molecules, which encode two proteins: the smaller segment encodes the $\mathrm{CP}$, and the larger one encodes the RdRp (Nibert et al., 2013). Extracting dsRNA from mycelial tissue of $C$. sacchari 125, recovered from sugarcane in Khuzestan, Iran, indicated a potential mycovirus infection. The electrophoresis analysis showed the extracted dsRNAs consist of more than the two linear dsRNAs of approximately 1.85 , and $1.65 \mathrm{kbp}$ that are presumed to be the viral genomic elements; they also contain a smaller dsRNA segment (about $1.27 \mathrm{kbp}$ ) that could be a satellite dsRNA or defective-interfering dsRNA (King et al., 2012) (Fig. 1). In some partitiviruses such as those infecting Rosellinia necatrix, Discula destructive, Gremminiella abietina and Atkinsonella hypoxylon, more than two linear dsRNAs, have been detected, thought to be satellites or defective RNAs (Chiba et al., 2013; Ghabrial et al., 2008). Analysis of the effects of subviral RNAs in partitiviruses are difficult because no reverse genetics system

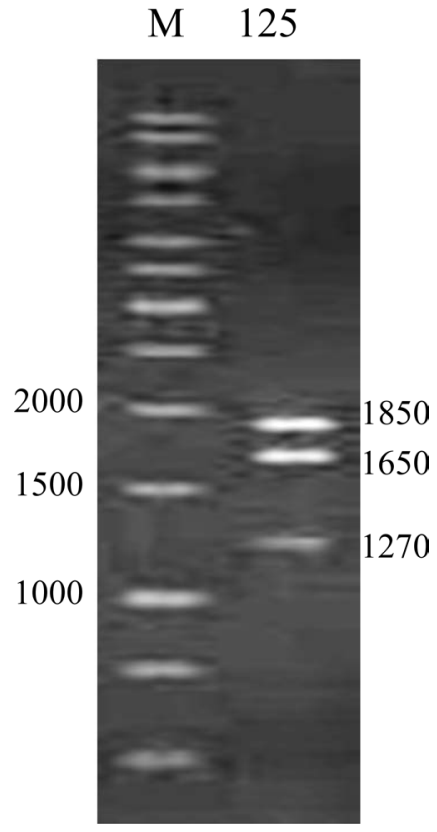

Fig. 1. Agarose gel electrophoresis of dsRNA elements associated with isolate 125 of Cytospora sacchari. Lane M, $1 \mathrm{~kb}$ DNA marker; numbers in left and right indicate bp. has been established (Chiba et al., 2013).

For confirming the identity of these fragments as dsRNAs, they were treated with DNase I and RNase A in high and low ionic strength buffer. These fragments were resistant to treatment by DNase I and RNase A in high salt concentrations, but they were sensitive to RNase A treatment in low salt concentrations (not shown). These results confirmed the identity of these elements as dsRNAs.

Elimination of dsRNAs. Many methods for eliminating dsRNA viruses from fungi have been reported (Márquez et al., 2007; Hammar et al., 1989). These methods met with varying degrees of success. Hammar et al. (1989) used cyclohexamide to eliminate dsRNAs in a strain of Leucostoma persoonii, some segments of dsRNAs were eliminated and partially cured strain was obtained. Márquez et al. (2007) successfully eliminated dsRNAs from Curvularia protuberata by desiccation and freeze-thawing. Elias and Coty (1996) used a single conidial transfer method for removing dsRNAs from six isolates of Aspergillus section flavi; except one isolate, these were cured completely or partially.

We attempted to eliminate CsPV from isolate 125 using treatment with cycloheximide in two concentrations ( 25 and $50 \mu \mathrm{g}$ ) and hyphal tip culture. The results showed that neither $25 \mu \mathrm{g}$ nor $50 \mu \mathrm{g}$ of cycloheximide affected the potential mycovirus infection in isolate 125 , and also hyphal tip culture had no effect on infected mycelia, and the dsRNAs were retained in C. sacchari isolate 125 (data not shown). Details of mycovirus biology are still scant, but it is clear that there is a great deal of variation, with some viruses being extremely unstable in culture, and others being recalcitrant to curing (M. Roossinck, unpublished). This makes detailed analysis of the effects of these viruses on their hosts very challenging.

Molecular characterization of dsRNA. The partial nucleotide sequence of isolate 125 was obtained by sequencing recombinant plasmid clones derived from a cDNA library. Twenty-four cDNA plasmid clones were randomly selected for sequencing in two directions. Sequence assembly of these cDNA clones and comparison with known mycoviruses using the BLAST program indicated that there was a gap, which was filled by PCR with specific primers, and we obtained a 1,284 base pair (bp) sequence. The analysis of the sequence with BlastN and BlastX programs revealed significant sequence similarities with the RNA-dependent RNA polymerase (RdRp) of viruses of the family Partitiviridae. Sequence similarity among partitiviruses and the obtained sequence of isolate 125 indicate that it is a novel 
Table 2. Amino acid identity between CsPV and other members of the genus Partitivirus

\begin{tabular}{|c|c|c|c|c|}
\hline Partitivirus $^{\mathrm{a}}$ & Sigla & $\%$ Identity & Overlap & Genbank accession no. \\
\hline Cytospora sacchari partitivirus & $\mathrm{CsPV}$ & - & - & KF697164 \\
\hline Penicillium stoloniferum virus $S$ & PsV-S & $76 \%$ & $100 \%$ & CAJ01909.1 \\
\hline Aspergillus ochraceous virus 1 & AoV1 & $71 \%$ & $99 \%$ & ABC86749.1 \\
\hline Botryotinia fuckeliana partitivirus 1 & BfPV1 & $70 \%$ & $99 \%$ & YP_001686789.1 \\
\hline Gremmeniella abietina $R N A$ virus MS1 & GaRV-MS1 & $71 \%$ & $99 \%$ & NP_659027.1 \\
\hline Aspergillus fumigatus partitivirus 1 & AfPV1 & $71 \%$ & $100 \%$ & CAY25801.2 \\
\hline Verticillium dahlia partitivirus 1 & VdPV1 & $70 \%$ & $100 \%$ & AGI52210.1 \\
\hline Discula destructiva virus 2 & DdV2 & $67 \%$ & $99 \%$ & NP_620301.1 \\
\hline Discula destructiva virus 1 & DdV1 & $67 \%$ & $100 \%$ & NP_116716.1 \\
\hline Ophiostoma partitivirus 1 & OPV1 & $67 \%$ & $97 \%$ & CAJ31886.1 \\
\hline
\end{tabular}

${ }^{a}$ The top nine distinct viruses returned by BLASTp are shown. For each virus, a representative isolate was selected for use in this table.

virus in the genus Partitivirus in the family Partitiviridae; we have tentatively designated it as Cytospora sacchari partitivirus (CsPV). The partial nucleotide sequence of CsPV has been deposited in GeneBank (accession no. KF697164).

The obtained sequence of CsPV can potentially encode a 405 amino acid (aa) protein. The search in BLASTP showed that this protein has similarity with RdRps of a number of fungal partitiviruses. Pairwise aa identities between $\mathrm{CsPV}$ and previously identified partitiviruses are presented in Table 2. The highest aa identity (76\%) is between CsPV and Penicillium stoloniferum virus $S$ (PsV-S). Blast search with deduced amino acid sequence reveals that this sequence has a single ORF. Search of the conserved domain database (CDD) revealed a significant match with conserved domains related to the Partitivirus RdRp (RNA-depRNAP, cd01699). To define the relationship among the putative RdRp of this virus and the previously characterized partitiviruses, multiple sequence alignment was conducted. The alignment shows four amino acid conserved domains (I-IV) characteristic of partitivirus RdRps including the highly conserved GDD motif typical of RdRps in motif IV (Fig. 2).

A Bayesian phylogenetic analysis was conducted based on alignments of the putative amino acid sequence of RdRps of CsPV and selected members of the genus Partitivirus (Fig. 3). As expected, CsPV was included in a clade within the partitiviruses. Based on this analysis CsPV was clus-

\begin{tabular}{lccccccc} 
& \multicolumn{1}{c}{ I } & \multicolumn{2}{c}{ II } & & III & IV \\
CsPV & PKTRLVW & 55 & DFSAFDTTVP & 61 & GVPSGSWWTQMVDSVVN & 19 & VLGDDS \\
PSV-S & PKTRLVW & 55 & DFSGFDTKVP & 61 & GVPSGSWFTQMIDSVVN & 19 & VLGDDS \\
AoV1 & PKTRLVW & 55 & DFSSFDSKVP & 61 & GVPSGSWWTQMVDSVVN & 19 & VLGDDS \\
GaRV-MS1 & PKTRLVW & 55 & DFSSFDTKVP & 61 & GVPSGSWWTQMVDSVVN & 19 & VLGDDS \\
BfPV1 & PKTRLVW & 55 & DFSSFDTKVP & 61 & GVPSGSWWTQMIDSVVN & 19 & VLGDDS \\
VdPV1 & PKTRLVW & 55 & DFSAFDTKVP & 61 & GVPSGSWWTQMIDSVVN & 19 & VLGDDS \\
DdV1 & PKTRLVW & 55 & DFSAFDSKVP & 61 & GVPSGSWWTQIIDSVVN & 19 & VLGDDS \\
DdV2 & PKTRLIW & 55 & DFSAFDSKVP & 61 & GVPSGSWWTQIIDSVVN & 19 & VLGDDS \\
AfPV1 & PKTRLVW & 55 & DFSAFDARVP & 61 & GVPSGSWWTQMIYSVVN & 19 & VLGDDS \\
OPV1 & PKTRLVW & 55 & DFSSFDTKVP & 61 & GVPSGSWWTQMIDSVVN & 19 & VLGDDS \\
& $* * * * * *$ & & $* * * * * * *$ & & $* * * * * * * *: * * * *$ & & $* * * * *$
\end{tabular}

Fig. 2. Conserved amino acid motifs (I-IV) in RdRps of Cytospora sacchari partitivirus and other members of Partitivirus. Asterisks indicate identical residues; conserved and semi-conserved amino acid residues are indicated by colons and dots, respectively, as defined in the ClustalW program. Numbers between motifs correspond to the number of amino acid residues separating the motifs. Abbreviations of virus names and sequence accession numbers are shown in Table 2. 


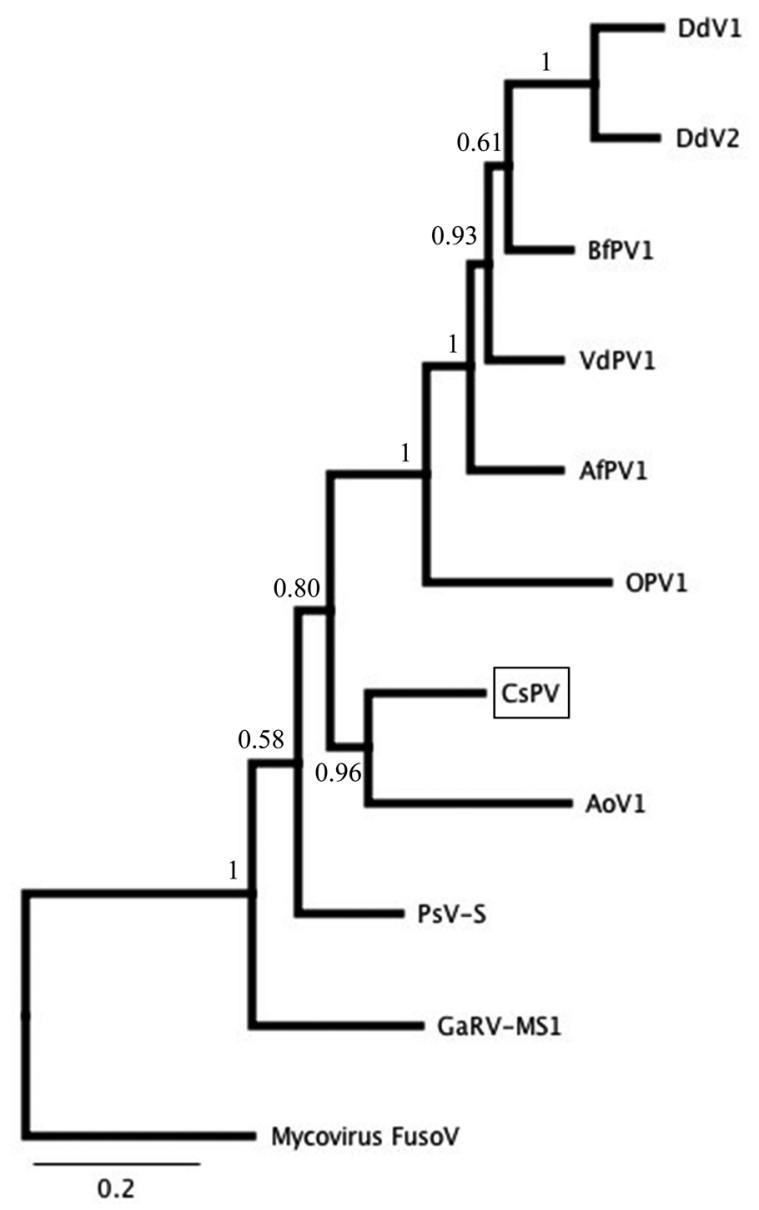

Fig. 3. Phylogenetic analysis based on amino acid sequences of RdRps of CsPV and selected members of Partitivirus. Bayesian analysis was done using the MrBayes plugin in Geneious software. Posterior probabilities are indicated by numbers at the nodes. The accession numbers of sequences used in the analyses are given in the Table 2. Mycovirus FusoV, Fusarium solani virus 1 (accession no. BAA09520), was used as an outgroup.

tered with Aspergillus ochraceous virus 1 (ABC86749.1) in a clade with 0.9631 posterior probability.

Based on a recent phylogenetic analysis it seems that the taxonomy of the family Partitiviridae is due for some revisions (Crawford et al., 2006; Nibert et al., 2013). In the current classification of Partitiviridae, host range has an important role for genus divisions; fungal partitiviruses have been classified in the genus Partitivirus while plant partitiviruses have been placed in Alphacryptovirus or Betacryptovirus. However the discovery of plant-infecting partitiviruses in Primula malacoides (Li et al., 2009), and Cannabis sativa (Ziegler et al., 2012), and the recent phylogenetic results suggest that this criterion may not be appropriate for genus divisions in the family Partitiviridae (Nibert et al., 2013; Roossinck, 2010). The existence of plant-infecting viruses in the genus Partitivirus supports the possibility of horizontal transfer of these viruses between plants and fungi (Crawford et al., 2006; Ghabrial et al., 2008; Roossinck, 1997; Roossinck, 2010). In addition, evidence has been recently found for integration of partitivirus sequences into plant genomes (Chiba et al., 2011; Liu et al., 2010). Phylogenetic analysis based on aa sequences of RdRps of members of family Partitiviridae led to identification of two clusters in the genus Partitivirus, comprised of a mixture of fungal viruses and plant viruses (Ghabrial et al., 2008; Nibert et al., 2013), these two clusters may be marked as two subgroups (subgroup 1 and 2) in this genus (Crawford et al., 2006; Ghabrial et al., 2008). One of the taxonomic revisions based on these results is to divide the genus Partitivirus into two new genera (Nibert et al., 2013), although other revisions of the Partitiviridae family are probably also necessary (Roossinck, 2010).

Phylogenetic analysis of aa sequences of RdRps of the established members of genus Partitivirus and putative RdRp of CsPV showed that CsPV would be placed in one of these subgroups that contains fungal viruses, whereas the other one consists of a mixture of fungal viruses and plant viruses. Based on suggested revision, each of these subgroups could be considered as a new genus in the family Partitiviridae. CsPV with AoV1 form a cluster in one of these new genera.

In summary, we have identified a putative partitivirus associated with $C$. sacchari that we tentatively named CsPV. The attempts for removing the dsRNAs with treatment by cyclohexamide and hyphal tip culture were unsuccessful. This study is the first report of partitivirus infection in the plant pathogenic fungus $C$. sacchari.

\section{Acknowledgments}

This work was supported by the Huck Institute for Life Sciences, The Pennsylvania State University College of Agricultural Science, the US National Science Foundation Grant IOS1157148 to MR, and the University of Tehran Grant 7110012.6.21. The authors wish to thank Drs. X. Bao, L.M. Márquez and J.S. Pita for technical advice.

\section{References}

Adams, G. C., Roux, J. and Wingfield, M. J. 2006. Cytospora species (Ascomycota, Diaporthales, Valsaceae): introduced and native pathogens of trees in South Africa. Austral. Plant Pathol. 35:521-548.

Adams, G. C., Wingfield, M. J., Common, R. and Roux, J. 2005. Phylogenetic relationships and morphology of Cytospora 
species and related teleomorphs (Ascomycota, Diaporthales, Valsaceae) from Eucalyptus. Studies Mycol. 52:1-144.

Ahn, I.-P. and Lee, Y.-H. 2001. A viral double-stranded RNA upregulates the fungal virulence of Nectria radicicola. Mol. Plant-Microbe Interact. 14:496-507.

Chiba, S., Kondo, H., Tani, A., Saisho, D., Sakamoto, W., Kanematsu, S. and Suzuki, N. 2011. Widespread endogenization of genome sequences of non-retroviral RNA viruses into plant genomes. PLoS Pathog. 7:16.

Chiba, S., Lin, Y.-H., Kondo, H., Kanematsu, S. and Suzuki, N. 2013. Effects of defective interfering RNA on symptom induction by, and replication of, a novel partitivirus from a phytopahtogenic fungus, Rosellinia necatrix. J. Virol. 87:23302341.

Chiba, S., Salaipeth, L., Lin, U.-H., Sasaki, A., Kanematsu, S. and Suzuki, N. 2009. A novel bipartite double-stranded RNA mycovirus from the white root rot fungus Rosellinia necatrix: molecular and biological characterization, taxonomic considerations, and potential for biological control. J. Virol. 83:12801-12812.

Cortesi, P., McCulloch, C. E., Song, H., Lin, H. and Milgroom, M. G. 2001. Genetic control of horizontal virus transmission in the chestnut blight fungus, Cryphonectria parasitica. Genetics 159:107-118.

Crawford, L. J., Osman, T. A. M., Booy, F. P., Coutts, R. H. A., Brasier, C. M. and Buck, K. W. 2006. Molecular characterization of a partitivirus from Ophiostoma himal-ulmi. Virus Genes 33:33-39.

Dodds, J. A., Morris, T. J. and Jordan, R. L. 1984. Plant viral double-stranded RNA. Annu. Rev. Phytopathol. 22:151-168.

Drummond, A. J., Ashton, B., Buxton, S., Cheung, M., Cooper, A., Duran, C., Field, M., Heled, J., Kearse, M., Markowitz, S., Moir, R., Stones-Havas, S., Sturrock, S., Theirer, T. and Wilson, A. (2011). Geneious. 6.1 edn.,

Elias, K. S. and Coty, P. J. 1996. Incidence and stability of infection by double-stranded RNA genetic elements in Aspergillus section flavi and effects on aflatoxigenicity. Can. J. Bot. 74:716-25.

Fotouhifar, K.-B. 2007. Taxonomic research on Iranian formspecies of form-genus Cytospora Ehrenberg. University of Tehran, Karaj, Iran.

Fotouhifar, K.-B., Hedjaroude, G.-A. and Leuchtmann, A. 2010. ITS rDNA phylogeny of Iranian strains of Cytospora and associated teleomorphs. Mycologia 102:1369-1382.

Ghabrial, S. A. 1998. Origin, adaptation and evolutionary pathways of fungal viruses. Virus Genes 16:119-131.

Ghabrial, S. A., Ochoa, W. F., Baker, T. S. and Nibert, M. L. 2008. Partitiviruses: general features. In: Mahy BWJ, VanRegenmortel MHV (eds) Encyclopedia of Virology, vol 3. 3rd edn. Elsevier, Oxford, UK, pp 68-75.

Ghabrial, S. A. and Suzuki, N. 2009. Viruses of plant pathogenic fungi. Annu. Rev. Phytopathol. 47:353-384.

Hammar, S., Fulbright, D. W. and Adams, G. C. 1989. Association of double-stranded RNA with low virulence in an isoalte of Leucostoma persoonii. Phytopahtology 79:568-572.

Huelsenbeck, J. P. and Ronquist, F. 2001. MRBAYES: Bayesian inference of phylogenetic trees. Bioinformatics 17:754-755.

King, A. M. Q., Adams, M. J., Carstens, E. B. and Lefkowitz, E. J. (eds) 2012. Virus Taxonomy Ninth Report of the International Committee On Taxonomy of Viruses, vol 9. Elsevier Academic Press, San Diego, CA.

Li, L., Tiam, Q., Du, Z., Duns, G. J. and Chen, J. 2009. A novel double stranded RNA virus detected in Primula malacoides is a plant-isolated partitivirus closely related to partivirus infecting fungal species. Arch. Virol. 154:565-572.

Liu, H., Fu, Y., Jiang, D., Li, G., Xie, J., Cheng, J., Pend, Y., Ghabriel, S. A. and Yi, X. 2010. Widespread horizontal gene transfer from double-stranded RNA viruses to eukaryotic nuclear genomes. J. Virol. 84:11879-11887.

Márquez, L. M., Redman, R. S., Rodriguez, R. J. and Roossinck, M. J. 2007. A virus in a fungus in a plant --three way symbiosis required for thermal tolerance. Science 315:513-515.

Milgroom, M. G. and Cortesi, P. 2004. Biological control of chestnut blight with hypovirulence: a critical analysis. Annu. Rev. Phytopathol. 42:311-338.

Nibert, M. L., Tang, J., Xie, J., Collier, A. M., Ghabrial, S. A., Baker, T. S. and Tao, Y. J. 2013. 3D structures of fungal partitiviruses. Adv. Virus Res. 86:59-85.

Nibert, M. L., Woods, K. M., Upton, S. J. and Ghabrial, S. A. 2009. Cryspovirus: a new genus of protozoan viruses in the family Partitiviridae. Arch. Virol. 154:1959-1965.

Nuss, D. L. 1992. Biological control of chestnut blights: an example of virus-mediated attenuation of fungal pathogenesis. Microbiol. Mol. Biol. Rev. 56:561-576.

Nuss, D. L. 2005. Hypovirulence: mycoviruses at the fungalplant interface. Nat. Rev. Microbiol. 3:632-642.

Park, Y., Chen, X. and Punja, Z. K. 2006. Diversity, complexity and transmission of double-stranded RNA elements in Chalara elegans (synanam. Thielaviopsis basicola). Mycol. Res. 110:697-704.

Pearson, M. N., Beever, R. E., Boine, B. and Arthur, K. 2009. Mycoviruses of filamentous fungi and their relevance to plant pathology. Mol. Plant Pathol. 10:115-128.

Roossinck, M. J. 1997. Mechanisms of Plant Virus Evolution. Annu. Rev. Phytopathol. 35:191-209.

Roossinck, M. J. 2010. Lifestyles of plant viruses. Phil. Trans. Roy. Soc. B 365:1899-1905.

Roossinck, M. J., Saha, P., Wiley, G. B., Quan, J., White, J. D., Lai, H., Chavarría, F., Shen, G. and Roe, B. A. 2010. Ecogenomics: Using massively parallel pyrosequencing to understand virus ecology. Mol. Ecol. 19S1:81-88.

Sivanesan, A. 1983. Cytospora sacchari. CMI Description of Pathogenic Fungi and Bacteria. CAB International, Wallingford, UK.

Snyder, B. A., Adams, G. C. and Fulbright, D. W. 1989. Association of a virus-like particle with a diseased isolate of Leucostoma persoonii. Mycologia 81:241-247.

Taher-Khani, K., Ershad, J. and Nassirpour, N. 2004. Study of 
cytospora sheath-rot of sugarcane in Khuzestan. Paper presented at the 16th Iranian Plant Protection Congress, Tabriz, Iran, 28 Aug-1 Sept.

Yaegashi, H., Kanematsu, S. and Ito, T. 2012. Molecular characterization of a new hypovirus infection a phytopathogenic fungus, Valsa ceratosperma. Vir. Res. 165:143-150.

Yu, J., Kwon, S.-J., Lee, K.-M., Son, M. and Kin, K.-H. 2009. Complete nucleotide sequence of double-stranded RNA viruses from Fusarium graminearum strain DK3. Arch. Virol.
154:1855-1858.

Yu, X., Li, B., Fu, Y., Jiang, D., Ghabrial, S. A., Peng, Y., Xie, J., Cheng, J., Huang, J. and Yi, X. 2010. A geminivirus-related DNA mycovirus that confers hypovirulence to a plant pathogenic fungus. Proc. Nat. Acad. Sci. USA 107:8387-8392.

Ziegler, A., Matousek, J., Steger, G. and Schubert, J. 2012. Complete nucleotide sequence of a cryptic virus from hemp (Cannabis sativa). Arch. Virol. 157:383-385. 